\title{
THE OSMOTIC RESISTANCE (FRAGILITY) OF HUMAN RED CELLS ${ }^{1}$
}

\author{
BY ARTHUR K. PARPART, PHILIP B. LORENZ, ETHEL R. PARPART, JOHN R. \\ GREGG, AND AURIN M. CHASE
}

\author{
(From the Physiological Laboratory, Princeton University, Princeton, N. J., and The Marine \\ Biological Laboratory, Woods Hole, Mass.)
}

(Received for publication August 31, 1946)

The degree of resistance of red cells to a decrease of the salt content of their environment has long been used experimentally as one measure of their viability and clinically as a diagnostic characteristic. The experimental basis for this measure has been the fact that when any red cell, of a population of red cells, reaches a certain volume (the hemolytic volume, Jacobs [1]), the hemoglobin of that cell diffuses to equilibrium inside and outside the cell, usually without rupture of the plasma membrane of the cell. Since any given population of red cells possesses individual cells which differ from one another in the volume at which hemoglobin is permitted to diffuse out, the osmotic resistance of such a population of red cells is assumed to follow a normal probability distribution. In fact, the "Fragility Test" ${ }^{2}$ is based on this assumption. This is a reasonable assumption for freshly collected red cells of normal man (Figure 1) (Hunter [2], Guest and Wing [3]).

Clinical data on fragility and frequently laboratory experimental data have been collected by visual selection of the salt concentration at which the maximal and minimal degree of hemolysis occurs. Unfortunately this method of observation means that the data have been obtained on the least accurate parts of the osmotic resistance curve, namely at its extremes. In these extreme regions of the curve, small differences in the degree of hemolysis correspond with large differences of salt concentration (Figure 1); and, hence, one would expect divergent results, particularly since

\footnotetext{
1 The work described in this paper was done under a contract recommended by the Committee on Medical Research, between the Office of Scientific Research and Development and Princeton University.

2 The term "Osmotic Resistance" will be used throughout this paper in a sense that is somewhat analagous to the term "Fragility." It is used because it more adequately defines the physical changes occurring in red cells under these conditions than does the term fragility.
}

subjective, visual observation of the degree of hemolysis has been used.

During the course of studies on the storage of whole blood it became necessary to determine accurately the variation in osmotic resistance of stored red cells. A method was devised for this purpose which in some respects is similar to that of Hunter (2). It took into account, however, several factors which markedly affect the normal osmotic resistance (Jacobs and Parpart [4]). The chief factor is the $\mathrm{pH}$ of the sodium chloride solutions (Figure 1). It is obvious from these curves that it is necessary to buffer the salt solutions. For this reason a stock solution was prepared containing the following: 180.00 grams $\mathrm{NaCl}, 27.31$ grams $\mathrm{Na}_{2} \mathrm{HPO}_{4}, 3.74$ grams $\mathrm{NaH}_{2} \mathrm{PO}_{4}$, all made up to 2 liters with distilled water. This "Stock NaCl-PO" solution is equivalent to a 10 per cent solution of $\mathrm{NaCl}$ and will keep for a number of months.

The salt concentrations for measurement of the osmotic resistance were prepared from this stock solution as follows :

A calibrated $50 \mathrm{ml}$. burette was filled with the "Stock $\mathrm{NaCl}-\mathrm{PO}$ " solution and the volumes given in column 2, Table I, run into a 250-ml. volumetric flask. This was

TABLE I

\begin{tabular}{|c|c|c|}
\hline Column 1 & $\begin{array}{c}\text { Column } 2 \\
\text { Stock } \mathrm{NaCl}-\mathrm{PO} \text {, } \\
\text { made up to } \\
250 \mathrm{ml} .\end{array}$ & $\begin{array}{c}\text { Column } 3 \\
\text { Stock } \mathrm{NaCl}-\mathrm{PO} \\
\text { made up to } \\
250 \mathrm{ml} \text {. } \\
\text { "Complementary } \\
\text { Solutions" }\end{array}$ \\
\hline $\begin{array}{c}\text { per cent } \\
0.8 \\
0.75 \\
0.70 \\
0.65 \\
0.60 \\
0.55 \\
0.50 \\
0.45 \\
0.40 \\
0.35 \\
0.30 \\
0.25 \\
0.20 \\
0.10\end{array}$ & $\begin{array}{c}m l . \\
20.00 \\
18.75 \\
17.50 \\
16.25 \\
15.00 \\
13.75 \\
12.50 \\
11.25 \\
10.00 \\
8.75 \\
7.50 \\
6.25 \\
5.00 \\
2.50\end{array}$ & $\begin{array}{c}m l . \\
30.00 \\
31.25 \\
32.50 \\
33.75 \\
35.00 \\
36.25 \\
37.50 \\
38.75 \\
40.00 \\
41.25 \\
42.50 \\
43.75 \\
45.00 \\
47.50\end{array}$ \\
\hline
\end{tabular}

made up to the 250-ml. mark with distilled water and put into a glass stoppered pyrex bottle labeled with the salt concentration shown in column 1 . The $\mathrm{pH}$ of these salt 


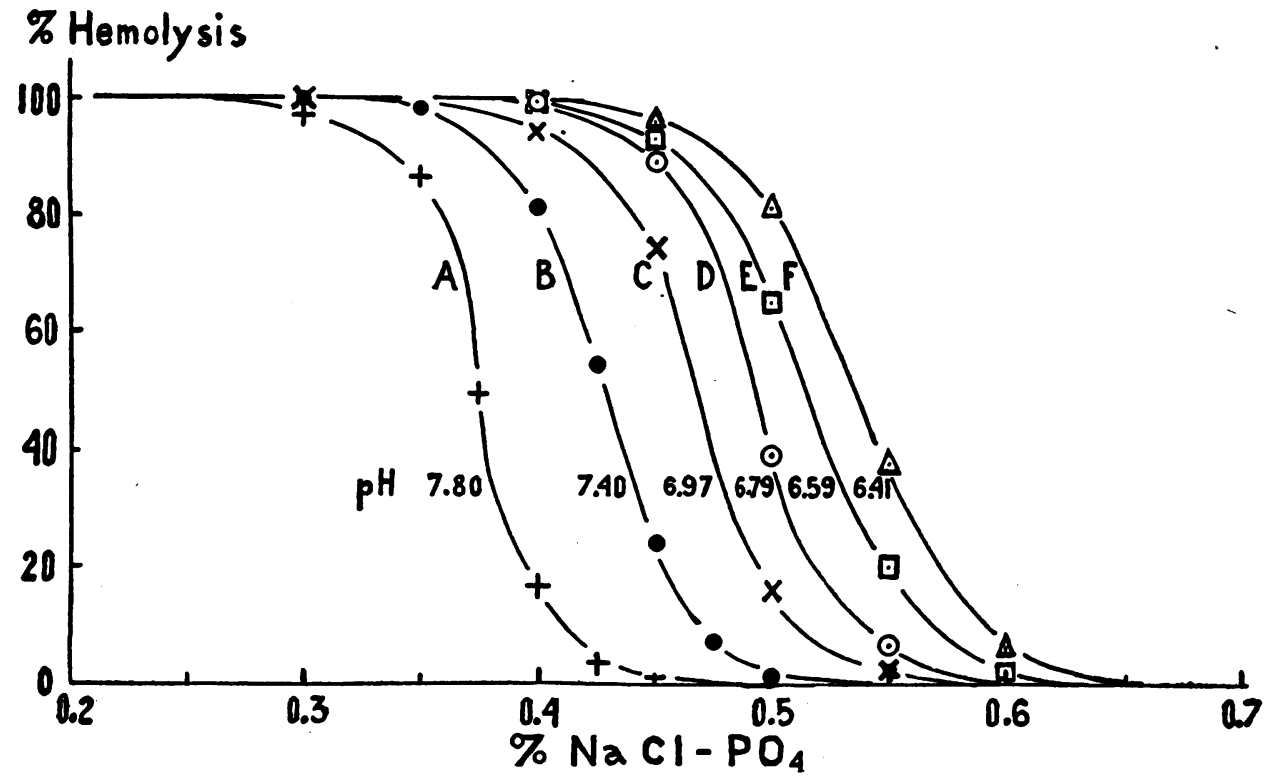

Fig. 1. Osmotic Resistance Curves of Normal Human Blood (Male, White) as Affected by the PH of the Salt Solutions

The per cent $\mathrm{NaCl}-\mathrm{PO}$, is equivalent to per cent $\mathrm{NaCl}$ of the usual fragility plot. Curve $\mathrm{B}$ is the average of determinations on the blood of 12 normal young men, no individual sample of which varied by more than 0.015 per cent $\mathrm{NaCl}$ from the average.

solutions is 7.40. The remainder (as shown in column 3, Table I) of each $50 \mathrm{ml}$. of Stock $\mathrm{NaCl}-\mathrm{PO}_{4}$ used for a particular salt concentration was also run into a $250-\mathrm{ml}$. flask made up with distilled water and stored in pyrex bottles labeled $\mathrm{C}_{0.8} ; \mathrm{C}_{0.75}$, etc.

The osmotic resistance series was set up by transferring $5 \mathrm{ml}$. of each of the salt concentrations to centrifuge tubes and adding $0.020 \mathrm{ml}$. of citrated blood ( $4 \mathrm{mgm} . \mathrm{Na}_{3} \mathrm{C}_{6} \mathrm{H}_{5} \mathrm{O}_{7}$. $2 \mathrm{H}_{2} \mathrm{O}$, added dry, per $\mathrm{ml}$. blood). The transfers were made with a 5-ml. syringe fitted with a 3 -inch No. 18 needle, and the blood was added from a hemoglobin pipette. The blood and the salt solution were equilibrated for 45 minutes. At this time the hemolytic process was stopped by the addition of the corresponding "Complementary Solution" ( $\mathrm{C}_{0.8} ; \mathrm{C}_{0.75}$, etc.), column 3 , Table I. Thus, the osmotic pressure around the unhemolyzed cells was returned to normal tonicity and further hemolysis stopped.

The percentage hemolysis was then determined either by a calibrated photoelectric densitometric method (Parpart [5]) ; or by centrifuging of the blood-salt solutions for 5 minutes at 1,500 r.p.m.; removing ${ }^{3}$ the supernatant cell-free hemoglobin solution and determining its concentration in a photoelectric colorimeter at the wave length $540 \mathrm{~m} \mu$.

Calibration for the per cent hemolysis was run on the

8 A syringe fitted with a long No. 18 needle, whose end is bent up to form a $J$, is convenient for removing the hemoglobin solution. same sample of blood. Where a photoelectric colorimeter is used to read the amount of hemoglobin in the supernatant solution, the calibration is performed as follows:

Transfer $5 \mathrm{ml}$. of 0.1 per cent $\mathrm{NaCl}-\mathrm{PO}_{4}$ solution to a test tube and add $0.020 \mathrm{ml}$. of blood; allow to stand for 15 minutes, then add $5 \mathrm{ml}$. of $\mathrm{C}_{0.1}$. Mix well and read in colorimeter. This reading gives the value for 100 per cent hemolysis. If the hemoglobin solutions in the particular photoelectric system used have been shown to obey Beer's Law, the per cent hemolysis in the various salt solutions may be calculated as follows:

$$
\frac{D_{\text {exp. }}}{D_{100 \text { per cont }}} \times 100=\text { per cent hemolysis }
$$

where the optical density, $D$, equals the $\log _{10}$ of the reciprocal of the transmission value obtained in the colorimeter. $D_{100 \text { per cent }}$ is that for the calibration solution; $D_{\text {oxp. }}$ is that for the supernatant fluid of any particular blood-salt solution.

In the practical use of this method one soon learns that not all of the 14 salt solutions recommended in Table I need be used for every sample of blood. Occasionally, finer gradations of salt concentration (e.g., $0.325,0.375$, $0.425,0.475$ etc.), may be needed. Such intermediate salt concentrations are readily prepared by mixing equal volumes of the salt solution in Table I above and below the desired concentration.

Two very useful criteria of osmotic resistance come out of data obtained in this way. By using 


\section{\% Hemolysis}

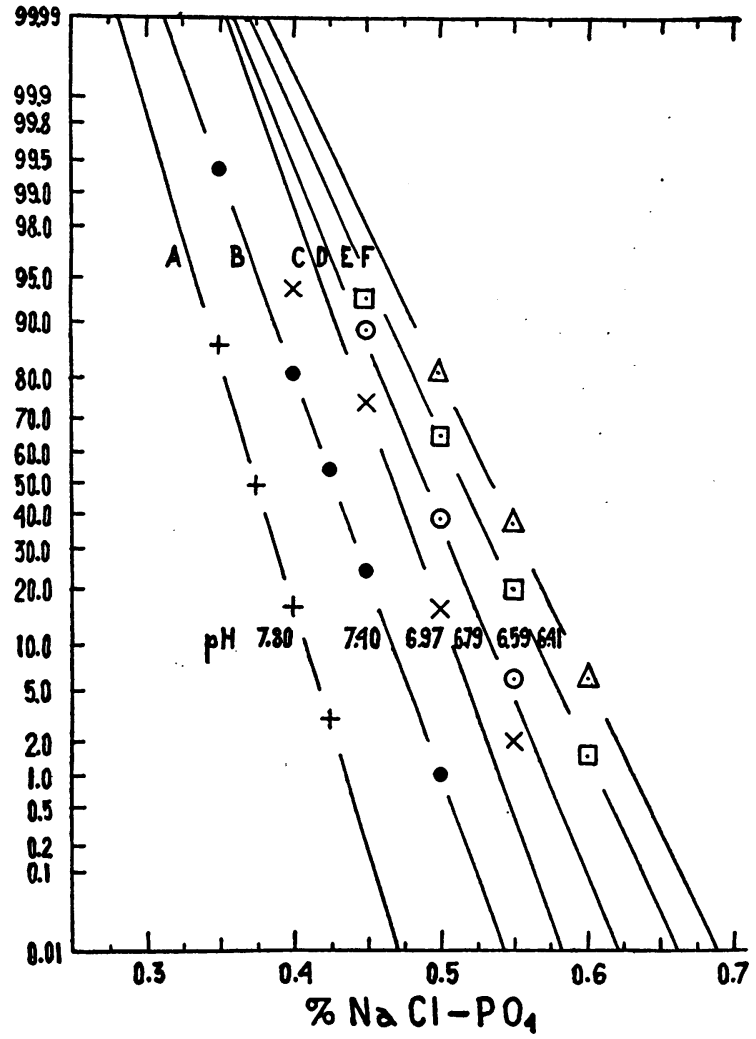

Fig. 2. A Probability Plot of the Osmotic Resistance Curves of Figure 1

This figure illustrates the ease with which the spread and the median of osmotic resistance may be determined graphically.

Probability Paper, ${ }^{4}$ (Hunter [2]), the spread of the osmotic resistance and the median may be obtained graphically (Figure 2). It shoud be emphasized that accurate data on the spread and the median can be obtained only if 3 or more of the salt concentrations used give degrees of hemolysis between 10 per cent and 90 per cent (i.e., in the critical concentration range).

The importance of stopping the hemolytic process at a fixed time by the addition of the complementary solution, is illustrated in Figure 3. These data were obtained by putting $0.020 \mathrm{ml}$. of blood into 5-ml. samples of salt solution which had been brought to and were kept at the temperatures given and at the time indicated on the abscissa, adding $5 \mathrm{ml}$. of the complementary solution, and

4 Keuffel and Esser Probability Paper No. 359-23. determining the per cent hemolysis in the manner described. Red cells equilibrated for 45 minutes at $20^{\circ} \pm 0.1^{\circ} \mathrm{C}$. in a hypotonic salt solution causing about 20 per cent hemolysis, are very near the equilibrium per cent of hemolysis. At higher temperatures the equilibrium is attained more rapidly ( 5 to 10 minutes at $40^{\circ}$ ); the $Q_{10}$ is of the order of 2.6. At temperatures below $20^{\circ} \mathrm{C}$. a time increasingly longer than 45 minutes must be allowed for attainment of equilibrium, particularly for blood in salt solutions which cause less than 50 per cent hemolysis. At $10^{\circ} \mathrm{C}$. equilibrium is reached after about 2 hours. When a salt solution of low concentration, which brings about complete hemolysis, is used the equilibrium is reached in a few minutes even at $10^{\circ} \mathrm{C}$., (Jacobs, Glassman and Parpart [6]).

If room temperatures fluctuate widely, consistent data on the osmotic resistance can be obtained only by equilibrating the blood-salt solutions in a water bath the temperature of which does not vary by more than a degree. A further, though less striking, illustration of this point is presented in the data on the spread and median of the osmotic resistance of normal human blood at $10^{\circ}, 20^{\circ}, 30^{\circ}$ and $40^{\circ}$, as given in a probability plot (Figure 4 ). As would be expected the osmotic resistance increases (fragility decreases), with increasing temperature (Jacobs and Parpart [4]). Thus, the spread at $10^{\circ}$ is from 0.330 to 0.531 per cent $\mathrm{NaCl}$ -

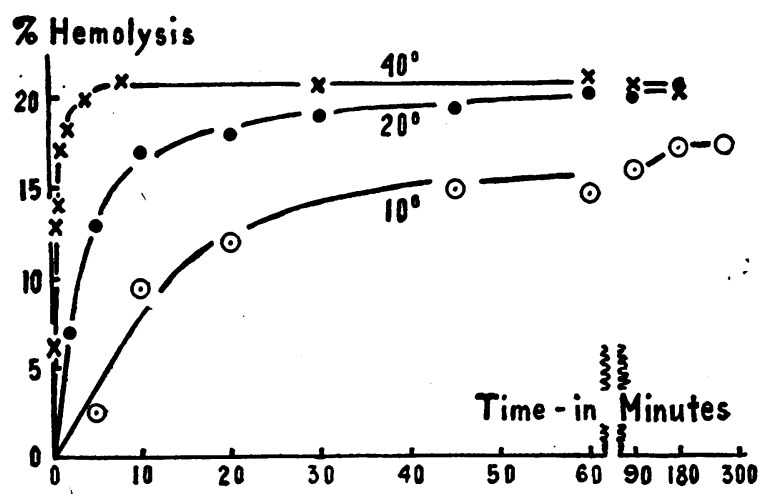

Fig. 3. Illustrates the Rate at Which the EQuilibrium Degree of Hemolysis is Attained at 3 TemPERATURES

Salt concentrations were chosen (from data in Figure 4) so that the equilibrium degree of hemolysis (17 to 20 per cent) would be approximately the same at the 3 temperatures. Details are given in the text. 


\section{\% Hemolysis}

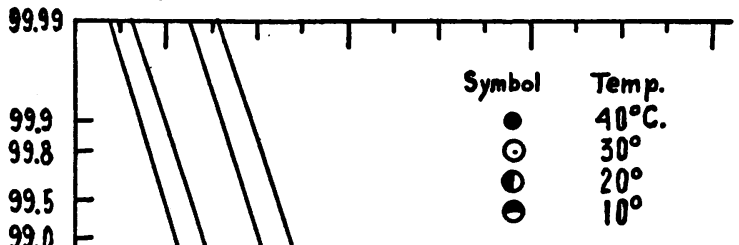

99.0
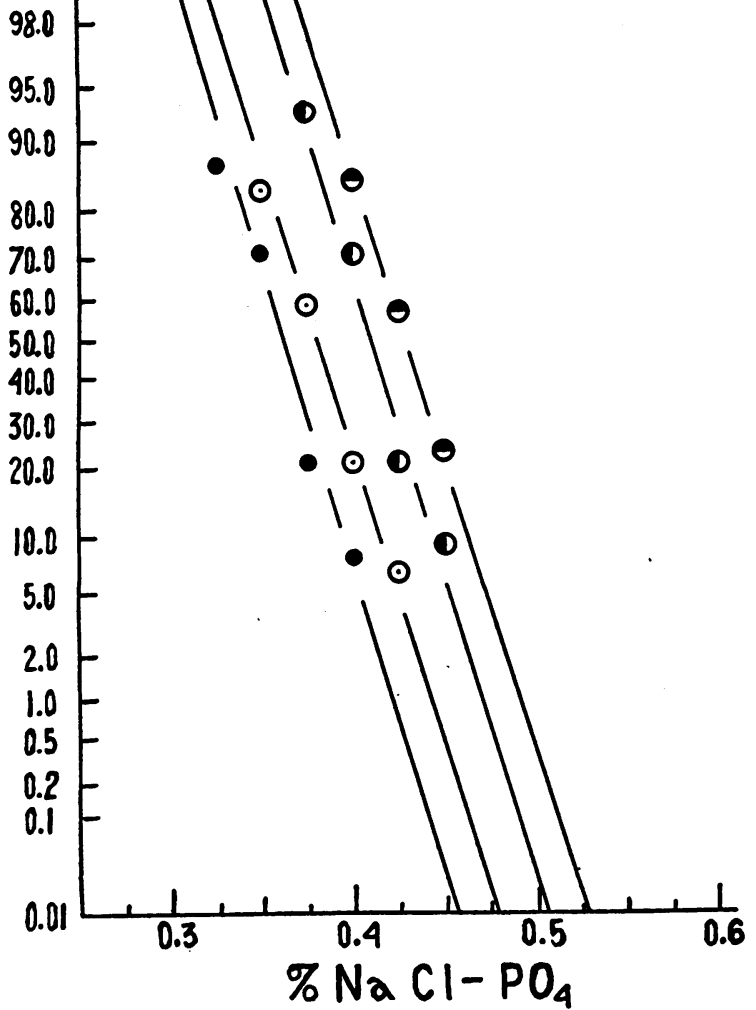

Fig. 4. Illustrates the Effect of Temperature on the Spread and Median of the Osmotic Resistance of Normal Human Blood

$\mathrm{PO}_{4}$, while that at $40^{\circ}$ is from 0.270 to 0.455 ; and the medians are 0.430 and 0.361 respectively.

It is obvious that temperature markedly affects the time at which the equilibrium degree of hemolysis may be attained, especially for blood-salt solutions in which low degrees (20 per cent) of hemolysis occur (Figure 3). Equally pertinent is the fact that once the equilibrium has been reached the temperature at which it is attained is a factor in determining the amount of hemolysis that will take place in a salt solution in the critical concentration range for solutions causing between 10 and 90 per cent hemolysis (see Figure 4).
The data on the effect of $\mathrm{pH}$ on the osmotic resistance (Figures 1 and 2) clearly demonstrate that this factor must be adequately controlled if reliable results are to be obtained. Examination of the data in Figure 2 will show that a change of $\mathrm{pH}$ by 0.1 of a $\mathrm{pH}$ unit is equivalent to altering the salt concentration by 0.01 per cent. The extreme variation for 12 normal adult males (curve $B$, Figure 2), is 0.02 per cent of salt concentration; if the $\mathrm{pH}$ had not been carefully controlled, this variation could have been caused by a shift of only 0.2 of a $\mathrm{pH}$ unit.

The osmotic resistance of blood may be greatly altered if it is collected under conditions where a large volume of an isosmotic glucose solution is added to it or where the salt content of the fluid surrounding the cells is reduced. Thus the red cells of blood collected by the method of De Gowin (7) have their median osmotic resistance (M.O.R.) at 0.800 per cent $\mathrm{NaCl}$ within 3 hours after collection, instead of at the normal M.O.R. of 0.425 per cent $\mathrm{NaCl}$ (curve $\mathrm{B}$, Figure 1). On the other hand, red cells resuspended in solutions of pure non-electrolytes (e.g. corn syrup), undergo rapid ion exchanges and salt losses, (Jacobs and Parpart [8]) which lead to an increase in their osmotic resistance. In short, the environment of the red cells prior to measuring their resistance to changes in osmotic pressure must be considered in the analysis of their behavior.

\section{SUMMARY}

1. The factors which affect the measurement of the osmotic resistance of red cells (human) are analyzed. A method for such measurements is presented.

2. The factors: $\mathrm{pH}$, temperature, rate of attainment of equilibrium, and chemical environmental changes each markedly influence the measurement of osmotic resistance. The magnitude and direction of their effects are considered.

\section{BIBLIOGRAPHY}

1. Jacobs, M. H., The complex nature of the effects of temperature on the rates of certain biological processes. The Am. Naturalist, 1928, 62, 289.

2. Hunter, F. T., A photoelectric method for the quantitative determination of erythrocyte fragility. J. Clin. Invest., 1940, 19, 691. 
3. Guest, G. M., and Wing, M., Osmometric behavior of normal human erythrocytes. J. Clin. Invest., 1942, 21, 257.

4. Jacobs, M. H., and Parpart, A. K., Osmotic properties of the erythrocyte. II. The influence of $\mathrm{pH}$, temperature, and oxygen tension on hemolysis by hypotonic solutions. Biol. Bull., 1931, 60, 95.

5. Parpart, A. K., The permeability of the mammalian erythrocyte to deuterium oxide. J. Cell. \& Comp. Physiol., 1935, 7, 153.

6. Jacobs, M. H., Glassman, H. N., and Parpart, A. K.,
Osmotic properties of the erythrocyte. VII. The temperature coefficients of certain hemolytic processes. J. Cell. \& Comp. Physiol., 1935, 7, 197.

7. De Gowin, E. L., Harris, J. E., and Plass, E. D., Studies on preserved human blood. I. Various factors influencing hemolysis. J. A. M. A., 1940, $114,850$.

8. Jacobs, M. H., and Parpart, A. K., Osmotic properties of the erythrocyte. VI. The influence of the escape of salts on hemolysis by hypotonic solutions. Biol. Bull., 1933, 65, 512. 